Werner Abraham and Jan-Wouter Zwart, eds. , Issues in Formal Germanic typology. Amsterdam.: Benjamins 2002, 141-178.

Wolfgang Klein

\title{
The argument-time structure of recipient constructions in German
}

\begin{abstract}
It is generally assumed that verbs have an 'argument structure', which imposes various constraints on the noun phrases that can or must go with the verb, and an 'event structure', which characterises the particular temporal characteristics of the 'event' which the verb relates to: this event may be a state, a process, an activity, an 'event in the narrow sense', and others. In this paper, it is argued that that argument structure and event structure should be brought together. The lexical content of a verb assigns descriptive properties to one or more arguments at one or more times, hence verbs have an 'argument-time-structure' (AT-structure). Numerous morphological and syntactical operations, such as participle formation or complex verb constructions, modify this AT-structure. This is illustrated with German recipient constructions such as ein Buch geschenkt bekommen or das Fenster geöffnet kriegen.
\end{abstract}

Begriffe, welche sich bei der Ordnung der Dinge als nützlich erwiesen haben, erlangen über uns leicht eine solche Autorität, daß wir ihres irdischen Ursprungs vergessen, und sie als unabänderliche Gegebenheiten hinnehmen. Sie werden dann zu 'Denkgewohnheiten', 'Gegebenen a priori' gestempelt. Der Weg des wissenschaftlichen Fortschritts wird durch solche Irrtümer oft für lange Zeit ungangbar gemacht. Es ist deshalb durchaus keine müßige Spielerei, wenn wir darin geübt werden, die längst geläufigen Begriffe zu analysieren und zu zeigen, von welchen Umständen ihre Berechtigung und Brauchbarkeit abhängt.

Einstein,

\section{Introduction}

For reasons hidden in the haze of history, grammarians often prefer to describe compound constructions not so very much according to the rules by which they are composed but in relation to other expressions which are felt to be akin. Thus, the German expression wurde geöffnet involves four components:

- there is the verb stem öffn-,

- there is a morphological operation which turns this verb stem into the form geöffnet,

- there is another verb stem werd-which is syntactically combined with geöffnet, and finally, 
- there is another morphological operation which turns werd-into the 'finite' form wurde.

Therefore, it would appear natural to ask what each of these ingredients contributes to form and meaning of the entire expression wurde geöffnet. When this question has found a satisfactory answer, one might proceed to the question of how the construction relates to other expressions, such as öffnete or bekam geöffnet. Common practice, however, is to begin with the latter: various expressions are seen as 'converses', as 'diathetical variants', as varying possibilities to realise the argument structure of verb stem. This practice suggests questions as the following ones:

(i) What is responsible for the 'passive' nature of wurde geöffnet - the participle, the auxiliary or the - compositional or non-compositional - combination of both?

(ii) Why do some verb stems tolerate 'passivization', whereas others don't? Why do some German verbs only allow impersonal passives, such as Es wurde getanzt?

(iii) How does 'passivization' change the argument structure?

(iv) How do active and passive differ with respect to topic-focus-properties?

(v) Is the combination of sei- with a participle, as in war geschlossen, a passive, too ('Zustandspassiv'), or should it rather be seen as a predicative construction?

In no case is the answer straightforward. Consider, for example, (i). The participle also occurs in constructions, where it has no 'passive flavour' at all, such as in the Perfekt Karl hat die Tür geöffnet. This also applies to werd-, which can be used to mark the future or modality, as in er wird arbeiten, or the transition to a state, as in er wurde grün. Hence, we seem forced to stipulate systematical ambiguity, or we sacrifice compositionality.

There is no doubt that each of these questions is interesting and worth to be investigated. But if we want to understand form and meaning of compound expressions - and this is what grammar is about -, then they should come second. If par ordre du moufti or by a strange turn of language development the expression die Katze öffnete die Tür were all of a sudden removed from German, then the expression die Tür wurde von der Katze geöffnet were composed as before, and had the same meaning, and a grammarian who deserves this name should be able to describe its formal and semantical composition without recurring to other, similar constructions.

In this paper, I will try to do this for a German construction which is traditionally called 'Rezipientenpassiv'. These are expressions like (Er) bekam einen Hering abgenommen, (Sie) kriegte von ihrer Schwester geholfen, (Er) erhielt einen leichten Verweis erteilt and similar ones. They are composed just as wurde geöffnet except that the second verb stem is bekomm-, krieg-, erhalt- ${ }^{1}$ rather than werd- and that there are two arguments rather than one. In what follows, I will try to describe what the four components verb stem, participle formation, attachment of bekomm- and finite marking of the latter contribute to the meaning of the entire construction. It will turn out that this is not possible without looking at the 'argument-time'structure initially provided by verb stem and successively modified by

${ }^{1}$ There are stylistical and, to a lesser extent, also semantical differences between these three verb stems; but these will not be discussed here, as little as the fact that some speakers consider some of these forms to be vernacular. I shall normally use examples with bekomm-, althought in some variants of German, including my own, krieg- is preferred. 
additional operations. The central aim of this paper is to illustrate this mechanism. No attempt is made to cover all idiosyncrasies of the 'Rezipientenpassiv' as known from the literature, nor will I systematically discuss previous analyses of this construction. I would like to stress, however, how much I owe to this literature, notably Reis 1976, 1985, Eroms 1978, Wegener 1985 and Leirbukt 1997; the latter work contains an excellent summary of the state of our knowledge in this domain.

\section{The range of bekomm--constructions}

Not all constructions with bekomm- are considered to be a Rezipientenpassiv, but all of them somehow convey the notion of being 'receptive'. Following a general maxim in research, I will therefore start with the assumption that the contribution which bekomm- has to make to the entire construction is always the same. It may well turn out that there are exceptions to this assumption; but as any exception, they would be deplorable and weaken the linguistic analysis. Here, as anywhere else in language, there are three reasons that might speak against a uniform analysis. Expressions can be ambiguous, they can be idiomatised, and they can exhibit idiosyncratic properties. In German, the morphological formation of the "past participle' is a comparatively regular process; but there are ambiguous forms, such as verbraucht, there are idiomatised usages, such as eine geschlossene Veranstaltung, and there are idiosyncrasies, such as the suppletive form gewesen. The mere existence of these pecularities does not speak against the idea of a analysis which tries to subsume all observable phenomena under a small set of simple principles and to reduce the number of exceptions to the minimum; these exceptions then must be individually listed in the lexicon.

In what follows, I shall use abbreviations $\mathrm{NP}_{\mathrm{N}}, \mathrm{NP}_{\mathrm{A}}$ and $\mathrm{NP}_{\mathrm{D}}$ for a noun phrase marked as nominative, accusative and dative, respectively; PART refers to the past participle, and $\mathrm{V}$ is a verb $\mathrm{stem}^{2}$ which underlies this participle and carries the lexical content.

\section{1 bekomm, $\mathrm{NP}_{\mathrm{N}}$ and $\mathrm{NP}_{\mathrm{A}}$}

This usage is highly productive. Typical examples are Hildegard bekam Angst/wacklige Knielein Kind/eine Krawatteleine neue Naseleinen Kuss/die Freiheit/ein würdiges Begräbnis. As the examples illustrate, the $\mathrm{NP}_{\mathrm{A}}$-referent can vary considerably: virtually everything that can be 'had' is possible, as well as some entities that cannot be had, such as a kiss: one may 'get' a kiss, but not 'have' a kiss. The $\mathrm{NP}_{\mathrm{N}}$-referent is normally animate, but there are exceptions, such as die Tür bekam einen neuen Anstrich (Reis 1976). Another feature is without exception: the $\mathrm{NP}_{\mathrm{N}}$-referent is inevitably characterised at two distinct temporal intervals. If the sentence Hildegard bekommt einen Schnupfen is true, then there must be a first time $t_{1}$ at which she does not have a cold, and a second time $t_{2}$ at which she does have it. Hence, V bekomm- expresses a change of state with respect to the argument expressed by $\mathrm{NP}_{\mathrm{N}}$. Is bekomm- agentive? This is not plausible, given its receptive nature. But a short look at the examples shows that the situation is not straightforward. As all state changes, the transition expressed by bekomm- must have a cause or several causes, and in many cases, one of these causes is the activity of a person. This person can be the referent of $\mathrm{NP}_{\mathrm{N}}$ (Hildegard bekam ein Kind) as well as the referent of some other NP (vom Briefboten). But the use of

${ }^{2}$ By 'verb stem', I mean the verb as it appears in the lexicon, i.e., before any inflectional morphology is applied to it. For simplicity's sake, the term is meant to include forms such as schlaf-, but also compound cases such as einschlaf-. 
bekomm- in this construction does not require that a person referred to by $\mathrm{NP}_{\mathrm{N}}$ or to some other NP in the sentence performs some activity without which the change of state would not occur. What is crucial, are two other facts:

$$
\text { bekomm- with } \mathrm{NP}_{\mathrm{N}} \text { and } \mathrm{NP}_{\mathrm{A}} \text { requires that }
$$

a. there is a change of state,

b. which concerns properties of the referent of $\mathrm{NP}_{\mathrm{N}}$.

Alternatively, we can say that the $\mathrm{NP}_{\mathrm{N}}$-referent is lexically characterised at two time spans, which I will call FIRST TIME (FT) and SECOND TIME (ST), respectively.

\section{2 bekomm-, $\mathrm{NP}_{\mathrm{N}}, \mathrm{NP}_{\mathrm{A}}$ and non-verbal complements}

This construction, too, is highly productive. Examples include Notker bekam den Text zurück/einen Hieb aufs Ohr/die Kohlen in den Keller/das Gulasch nicht weich/das Hemd tadellos in Form. Essentially, it corresponds to the preceding one, except that the non-verbal complement introduces another property which applies to the $N P_{A}$-referent at $S L$, and only at $S L$. For the second time, the $\mathrm{NP}_{\mathrm{A}}$-referent is spatially or qualitatively characterised: the text is back, the coals are in the cellar, the gulash is not tender, the shirt is in perfect shape. The only potential exception to this is the hit, about which one cannot say that he is now, at SL, on the ear. Note that in exactly these cases, one cannot say that there is a have-relation between the $\mathrm{NP}_{\mathrm{N}}$-referent and the $\mathrm{NP}_{\mathrm{A}}$-referent; neither 'has' Notker the hit, nor is the hit on his ear. We shall book this case as 'exception A'and continue to speak of a 'have-relation' and a 'berelation' without permanently referring to this pecularity.

Thus, pattern 2.2 involves two changes of state: there is a change in the have-relation between the $\mathrm{NP}_{\mathrm{N}}$-referent and the $\mathrm{NP}_{\mathrm{A}}$-referent, and the $\mathrm{NP}_{\mathrm{A}}$-referent assumes the properties expressed by the complement: these two changes are somehow 'synchronised', i.e., they both occur from some given FT to some given ST:

$$
\begin{array}{lll}
\text { FT: } & \mathrm{NP}_{\mathrm{N}} \text { not have } \mathrm{NP}_{\mathrm{A}} & \mathrm{NP}_{\mathrm{A}} \text { not be COMPLEMENT } \\
\text { ST: } & \mathrm{NP}_{\mathrm{N}} \text { have } \mathrm{NP}_{\mathrm{A}} & \mathrm{NP}_{\mathrm{A}} \text { be COMPLEMENT }
\end{array}
$$

If the property expressed by the complement is spatial, then its restriction to SL is often marked by a special case - the accusative: in DEN Keller, rather than in DEM Keller. In this case, the adverbial is usually called 'directional'. I do not think, however, that a direction is indicated here; it is only indicated that the object in question occupies the place expressed by the complement at the second time and not at the first time. No such marking is available for qualitative properties such as weich or tadellos in Form. We do have it, however, in cases such as Hans verwandelte sich in einen Werwolf, where being a werewolf is assigned to $\mathrm{NP}_{\mathrm{N}}$ only at ST, or in Er teilte den Kuchen in drei gleiche Teile, where the cake is in parts only at SL. Somehow, the accusative marking seems therefore akin to the idea that there is 'a second time' - a point to which we shall return shortly.

German also has constructions such as Notker bekam den Text auf dem Tisch, i.e., with a dative. It is possible, for example, when Notker got the text on the table and someone else (Alkuin?) got the text on the shelf. Intuitively, the dative complement auf dem Tisch belongs much closer to the $\mathrm{NP}_{\mathrm{A}}$. Therefore, it is traditionally analysed as a part of that NP, an analysis which is supported by the fact that the entire sequence den Text auf dem Tisch can be moved in front of the finite verb: den Text auf dem Tisch bekam Notker. This reasoning depends crucially on the assumption that 'NP-hood' is determined by distributional criteria 
like the possibility of moving ('Verschiebeprobe') - an assumption which is firmly established in the tradition but perhaps not as self-evident as one might want to have it. What is beyond doubt, however, is the difference between the temporal characteristics of bekam den Text auf den Tisch and bekam den Text auf dem Tisch: in the latter case, the assignment of the spatial property, being on the table, is not confined to ST, as is the case with auf den Tisch; in fact, it is often, though not necessarily understood to apply only during FT, i.e., to the time when Notker still does not have it. This is not necessary, however, as is illustrated by examples such as Notker bekam das Telegramm in Freising.

Is the $\mathrm{NP}_{\mathrm{N}}$-referent the 'agent'? The situation appears to be the same as with pattern 2.1. The coals may be in the celler due to Notker's efforts, but may it also be that someone else got them there for him. Similarly, it is open whether he himself tried to prepare the gulash or someone else who brought it to him. Hence, the $\mathrm{NP}_{\mathrm{N}}$-referent can be an agent but need not. ${ }^{3}$

\section{3 bekomm-, $\mathrm{NP}_{\mathrm{N}}, \mathrm{NP}_{\mathrm{A}}$ and PART}

This is the pattern which is normally called 'Rezipientenpassiv'; examples are Otfried bekam den Text überreicht/einen Hieb verpasst/die Kohlen gebracht/das Gulasch verwürzt/das Hemd gebügelt. This case appears to be essentially as pattern 2.2, except that the complement is a participle rather than a non-verbal expression. Two state-changes are involved, one concerning the have-relation between the $\mathrm{NP}_{\mathrm{N}}$-referent and the $\mathrm{NP}_{\mathrm{A}}$-referent, and the other one concerning the relation between the $\mathrm{NP}_{\mathrm{A}}$-referent and the properties expressed by PART (in both cases with 'exception A'); these latter properties are expressed by PART: the text is in Otfried's hands, the coals are in the cellar, the gulash is inedible, the shirt is in perfect shape; what is unclear are the properties of the hit.

$$
\begin{array}{lll}
\text { FT: } & \mathrm{NP}_{\mathrm{N}} \text { not have } \mathrm{NP}_{\mathrm{A}} & \mathrm{NP}_{\mathrm{A}} \text { not be PART } \\
\text { ST: } & \mathrm{NP}_{\mathrm{N}} \text { have } \mathrm{NP}_{\mathrm{A}} & \mathrm{NP}_{\mathrm{A}}
\end{array}
$$

Is the $\mathrm{NP}_{\mathrm{N}}$-referent responsible for these two changes? This varies. It may well be that his efforts have led to the fact that his shirt was eventually ironed; but it may also be that someone else did this for him. It is somewhat difficult to bring yourself the coals, hence in this example, the $\mathrm{NP}_{\mathrm{N}}$-referent is probably not the 'agent'; but this really depends on the case; there does not seem to be any substantial difference to pattern 2.1 and 2.2. Differences, where present, result from the fact that the be-property of $\mathrm{NP}_{\mathrm{N}}$ is expressed by PART, rather than by a non-verbal expression. A PART such as gebügelt has a richer internal structure than a simple 'adjective' like glatt. In particular, the underlying V bügel-involves several arguments and several time spans: a time on which someone is active in a particular way, a time at which something does not have a particular property, and a later time at which it has this property. It appears that these inherent time variables are paralleled to FT and ST of bekam, hence that there is a 'synchronisation' of the main verb and V of PART. This results in certain intuitive differences between Er bekam das Hemd glatt and Er bekam das Hemd gebügelt. But they stem from the fact, that glatt and gebügelt have different inherent 'argument-time structures';

${ }^{3}$ In blatant contradiction to footnote 1 , let me add that this ambiguity does not apply in the case of erhalt-: here, the $\mathrm{NP}_{\mathrm{N}}$-referent cannot be the responsible agent. 
the contribution of bekomm- itself is the same.

\section{4 bekomm-, $\mathrm{NP}_{\mathrm{N}}, \mathrm{NP}_{\mathrm{A}}$ and $z u+$ infinitive}

This pattern is very productive, too; examples are Einhard bekam ein Buch zu lesen/Süppchen zu essen/viel zu tun. Differences to the preceding patterns result from the particular properties assigned to the $\mathrm{NP}_{\mathrm{A}}$-referent by the complement for SL. Just as in the 'static' counterparts Einhard hat ein Buch zu lesen or Einhard hat etwas zu tun, the construction zu+infinitive has a modal component: a book which he can read or should read, something which he can do or should do. In the static case, there seems to be a preference for (deontic) necessity, whereas in the bekomm-constructions, the preference goes towards possibility; but both readings are possible in either case. The 'agent' must be the $\mathrm{NP}_{\mathrm{N}}$-referent; in the example, it is Einhard who has to or may read the book, eat the soup or do a lot. This, too, is different from pattern 2.2; in sentences such as Notker bekam das Hemd gebügelt, Notker need not be the person who does the ironing.

\section{5 bekomm-, $\mathrm{NP}_{\mathrm{N}}, \mathrm{NP}_{\mathrm{A}}$ and several complements}

This pattern includes cases such as Isidor bekam den Text korrigiert zurück/korrigiert auf den Schreibtisch/korrigiert zugeschickt/korrigiert zu lesen. They correspond to the patterns discussed so far but are more complex and obey a number of peculiar restrictions. In none of these cases can the participle korrigiert be the last element: *Isidor bekam den Text zurück korrigiert/*auf den Schreibtisch korrigiert/*zugeschickt korrigiert/*zu lesen korrigiert. Note that Isidor bekam den Text korrigiert is possible, but it can have two readings. In one of these, the changes from 'have-not' to 'have' and from 'be-not-corrected' to 'be-corrected' are synchronised; in the other, it only matters that the text IS corrected when he gets it. This latter reading is brought out in the pair Isidor bekam den Text korrigiert, alle anderen bekamen ihn unkorrigiert. Hence, bekomm- and korrigiert only share ST but not necessarily FT: when Isidor has the book, it is corrected. But it could also have been corrected before, i.e., no synchronised state-of-change is required. This constellation is apparently not possible when two complements are involved. Then, the last one must be 'fully synchronised', whereas the preceding one can be 'partly synchronised'. We will come back to this important point in section 2.7 .

\subsection{Other constructions with bekomm-}

There are some idiosyncratic cases. For instance, bekomm- can combine with an $\mathrm{NP}_{\mathrm{N}}$ and PART, as in Die Kleine bekam geschimpft; kaum jemand bekam geholfen. Only very few PART, however, allow this construction. A second case is even more restricted; it requires an $\mathrm{NP}_{\mathrm{N}}$, a $\mathrm{NP}_{\mathrm{D}}$ and possibly some adjectival complement, as in Das viele Arbeiten bekommt mir nicht/nicht gut or Wohl bekomm's!. ${ }^{4}$ None of these constructions is productive, and they will not be considered here.

${ }^{4} \mathrm{I}$ assume that constructions such as Hartmann bekam zu essen is simply a variant of Hartmann bekam etwas zu essen, in which the NPA is omitted. This is only rarely possible. 


\subsection{A short summary}

In the simplest case, bekomm- expresses a 'dynamic have-relation' between the $\mathrm{NP}_{\mathrm{N}}$-referent and the $\mathrm{NP}_{\mathrm{A}}$-referent (always barring 'exception A' from section 2.2): there is a first time FT, at which the former does not have the latter, and a second time ST, where it does. This change of state may be paralleled by a second change which involves properties of the $\mathrm{NP}_{\mathrm{A}}$-referent, as expressed by some complement. Three types of complements were distinguished: nonverbal specifications of some qualitative or spatial property (pattern 2.2), past participles (pattern 2.3) and constructions with $z u$ +infinitive (pattern 2.4). Combinations of these are possible, but there are strong restrictions (pattern 2.5).

Differences arise from the way in which the 'argument-time structure' of the complement and of bekomm- are related to each other. If there is no complement, as in Notker bekam Angst, the problem does not arise, of course. If the complement is non-verbal and assigns a spatial property to the $\mathrm{NP}_{\mathrm{A}}$-referent, as in Notker bekam die Kohlen in den Keller, then the accusative in the complement marks that this property only applies to the $\mathrm{NP}_{\mathrm{A}^{-}}$ referent at the second time, i.e., when Notker has the coals. If there is no such marking, as in Notker bekam die Kohlen im Keller, then no such synchronisation is required, and we assume that im Keller somehow belongs 'closer' to the $\mathrm{NP}_{\mathrm{A}}$, whatever this may mean. If the nonverbal complement assigns a qualitative property to the $\mathrm{NP}_{\mathrm{A}}$-referent, as in Notker bekam das Hemd glatt, then the shirt must be smooth when he has it; but apparently, is is open whether it was smooth before. There may be a transition, for example if Notker tries hard to get it smooth; but there is also a reading where he just gets the shirt at a stage where this shirt is smooth. It appears, therefore, that the synchronisation is something like: the time of the shirt's being smooth must overlap the ST of bekomm-; it may therefore include the FT of bekomm-, but it need not; if, for example, Notker is the 'agent', it does; if he is only the 'recipient', it normally does not.

Synchronisation becomes more difficult if the complement itself has a richer internal temporal structure, as in the case of participles like gebügelt. It somehow involves an argument who does the ironing at some time, but it also involves two different property assignments to a second argument: there is a time where the argument is not smooth, and a time where it is (more or less) $)^{5}$ smooth. Thus, various synchronisations are imaginable in Otfried bekam das Hemd gebügelt; minimally, it is required that the shirt has the SL property of being smooth when Otfried has it (for example when it was ironed by someone else). But it may also be that Otfried himself is the 'agent' of bügel-, and then, there is a transition from Otfried having a not-smooth shirt to having a smooth shirt.

The situation may be still more complex when the complement is further enriched, as in the other patterns discussed above; hence, it we want to understand the nature of all of these constructions, we must look at the inherent 'argument-time structure' of the various expressions involved and at the way in which these structures are related to each other.

\footnotetext{
${ }^{5}$ Here, as elsewhere in the paper, I will not argue what precisely the various descriptive properties are. Clearly, an ironed shirt need not be 'smooth' (it never is when I iron it). But for one, a satisfactory description of word meaning is to my mind the most difficult task in linguistics - in particular because we lack the appropriate descriptive language; and for the other, this problem is not directly relevant to our present concern. For the sake of illustration, it will be necessary to use such predicates here, such as 'open' or 'smooth', but they should be seen as illustrations, indeed. I will also sometimes use abbreviations such as $\mathbf{P}, \mathbf{Q}$, etc., to this end.
} 


\section{Properties of argument-time pairs}

Ever since the Greek philosophers, grammarians use to say that nouns refer to objects (nomen significat rem aut corpus says Priscianus), and verbs refer to 'events' - i.e., states, processes, actions, 'events' in the narrower sense; I shall say 'situations'. As so many other ideas traded down from one generation to the next, this one has a flavour of truth; but at the same time, it is misleading. To which situation does öffn- refer? It is the entire sentence which refers to a situation, and $\mathrm{V}$ makes a - substantial - contribution to the description of this situation. Consider, for example, the situation referred to by the following sentence, when uttered on some occasion:

(4) Reinmar öffnete das Portal.

$\mathrm{V}$ öffn- indicates some properties which the two NP-referents have at some time intervals. The gate must first be not open and then open, Reinmar must do something, for example turn a knob and push the door into a certain direction, or push a button, or say 'Sesame, open! whatever. In other words, IT IS THE FUNCTION OF $\mathrm{V}$ TO INDICATE PROPERTIES OF ARGUMENT-TIME PAIRS.These pairs themselves are not expressed by $\mathrm{V}$ but by noun phrases, by adverbials, by morphological variation of the stem and perhaps by other means. Sometimes, they are to be derived by context. What $\mathrm{V}$ itself provides are open slots to be filled appropriately, i.e. pairs of argument-time variables. In what follows, I shall use A, B, C, $\ldots$ as variables for arguments and $t_{1}, t_{2}, t_{3}, \ldots$ as variables for time spans; an argument-time pair (briefly AT-pair) is denoted by $<\mathrm{A}, \mathrm{t}_{\mathrm{i}}>$. If will be helpful to consider some examples.

In 5 , there is only one argument variable and one time variable, and the descriptive property is 'open'. The argument variable is specified by das Portal, the time variable is only vaguely restricted by the morphological tense marking ${ }^{6}$ on the copula:

(5) Das Portal war offen.

In 5, there is only one argument variable, as well; but properties are assigned to it at two times, FT and ST:

(6) Das Portal öffnete sich.

The FT-property of the single argument is 'not open', the ST-property is 'open'. In this case, the argument-variable is filled twice, by an $\mathrm{NP}_{\mathrm{N}}$ and by sich. The two time-variables are not specified but restricted by the tense marking.

Let us now return to 4 . Here, $\mathrm{V}$ assigns varying properties to two entities at different times. The entity which specifies the first argument variable is said to do something, whatever this may be, and the entity which specifies the second argument variable is first said to be not open and then, to be open. Hence, we have three AT-pairs which are assigned descriptive properties by $\mathrm{V}$. The lexical meaning of a $\mathrm{V}$ can then be described as a Boolean cluster of elementary predications over AT-pairs (leaving aside whether the descriptive properties are adequately described by terms such as 'active', etc.):

$$
\text { a. offensei- open }<\mathrm{A}, \mathrm{t}_{\mathrm{i}}>
$$

${ }^{6}$ Note that the tense marking does not indicate the time of the situation, i.e., the time of the gate's being open. It only says that there is a time before the utterance time which overlaps with the door's being open (see Klein 1994). 
b. öffn-not-open $<\mathrm{A}, \mathrm{t}_{\mathrm{i}}>\&$ open $<\mathrm{A}, \mathrm{t}_{\mathrm{j}}>$

c. öffn-not-open $<\mathrm{A}, \mathrm{t}_{\mathrm{i}}>\&$ open $<\mathrm{A}, \mathrm{t}_{\mathrm{j}}>\&$ 'active' $<\mathrm{B}, \mathrm{t}_{\mathrm{k}}>$

This does not exhaust the lexical content of Vs. If there is more than one AT-specification, as in $7 \mathrm{~b}$ and $7 \mathrm{c}$, then the relationship between these must be indicated, too. In the first place, this includes the temporal relation between the time spans. Thus, $t_{j}$ must be AFTER $t_{i}$; this is what we covered above by the labels first time $\mathrm{ft}$ and second time ST. If there is a third time spans, as in 7c, the relation between $t_{k}$ (the time of B's being active) and $t_{i}$ as well as $t_{j}$ must be indicated, as well. For sentence 4 to be true, Reinmar may still push the button of his automatical gate opener, although the gate is already open. But the sentence is not true of the gate opened, indeed, but Reinmar started his activity only when it was already open. Thus, $t_{k}$ must overlap (briefly OVL) with $t_{i}$; it may but need not overlap with $t_{j}$.

There are other than merely temporal relations between different AT-specifications. In 4, for example, it does not suffice that Reinmar did something and the gate made a transition from not open to open. For this sentence to be true, this temporal coincidence must not be accidental: we assume that the latter were not the case if the former were not the case. In honour of David Hume, who first stated this counterfactual relation for 'causally connected' entities, I will say that a 'H-connection' may obtain between various AT-specifications. ${ }^{7}$ As is usually the case for lexical entries, a potential $\mathrm{H}$-connection between various ATspecifications may be individually marked for each entry or covered by a lexical default rule; this is an empirical issue which we will not follow up here; nor will I discuss the question whether there is reason to assume other non-temporal relations between several ATspecifications. $^{8}$

As any lexical entry, a $\mathrm{V}$ is a cluster of (minimally) three types of information: phonological, categorial (such as being a noun) and semantical. The latter is called here

${ }^{7}$ I have chosen to speak of "H-connection" instead of 'counterfactuality' for two reasons. First, I would want to avoid the interesting but extremely difficult question whether 'counterfactuality' yields an appropriate analysis of what we intuitiveley understand by 'causation' or of what linguists often understand by the primitive predicate CAUSE. Second, 'counterfactuality' is normally understood to relate to states of affairs in possible worlds. Hume himself rather thought of it as some connection in our mind. He writes (1748, section VII, §60): "we may define a cause to be an object, followed by another, and where all of the objects similar to the first are followed by objects similar to the second, Or in other words where, if the first object had not been, the second never had existed.' His idea is to define that kind of "necessary connection" in our mind which we intuitively understand under 'causation'. In Lewis' famous counterfactual analysis of causation, this cognitive aspect is absent (Lewis 1973). It is not clear how the AT-specifications of lexcial contents, or the substates of the entire situation partially described by them, fare in that regard. It may even be that some substate cannot be EXPRESSED (rather than OBTAIN or BE THOUGHT OF) without expressing some other substate. This is probably too weak; but I would like to leave this open at this point and subsume all of these possibilities under "H-connection". - It should also be noted that the notion of $\mathrm{H}$-connection, as used here, does not necessarily require a temporal sequence (as Hume himself assumes for his notion of causation). It may well be that the two specifications obtain at the same time. This applies, for example, to cases with 'ongoing input of activity', as in John was turning a big wheel, where the wheel would not turn without John's simultaneous activity.

${ }^{8} \mathrm{~A}$ good candidate is intentionality. One may argue, for example, that verbs such as to look for or to try include a 'intentionality relation' between the actitity of an argument and the second AT-specification of the other argument. 
lexical content. The lexical content of a verb has a STRUCTURAL COMPONENT and a DESCRIPTIVE COMPONENT. The structual component is the AT-structure, which consists of the various AT-pairs together with a specification of how these are related to each other. The descriptive component consists of the various qualititative or spatial properties assigned to an AT-pair. These two components can be coupled in different ways. They may be conflated into a single morpheme, for example, as is the case with öffn- (in both variants). In offensei-, the descriptive property is contributed by offen, whereas V sei- does not specify a qualitative or spatial property; it only has an AT-structure, and it can be made finite (in contrast to the other component offen). Other cases are possible, and we will return to some of these below.

In all languages, Vs can undergo numerous morphological and syntactical operations. These affect their AT-structure as well as their Descriptive Component. Thus, a compound expression such as sollte geöffnet worden sein können has a relative complex AT-structure which results from successive operations on the stem öffn-. Some of these enrichments are merely temporal, i.e., they lead, for example, to a 'later interval' of some particular argument; participle formation is of this sort. Other add descriptive content, such as the modal V soll-. In section 5, this will be discussed for the various complex expressions formed with bekomm-. First, however, I will briefly sum up in which way the present view at differs from the traditional perspective.

Conventional wisdom has it that Vs have an 'argument structure' and moreover, that Vs (and more complex expressions such as full VPs) can be classified according to their inherent temporal properties into 'event types', 'Aktionsarten' etc. They have an argument structure as well as an event structure. The present view takes these two notions together: Vs have an 'argument-time structure'. This may be a little step; but it has important consequences. If, for example, a V in itself contains several temporal variables, a notion such as 'event time' turns out to be a gross oversimplification: what, for example, is the 'event time' in 4: is it $t_{i}, t_{j}$ or $t_{k}$ ? Or is it some interval which contains all or some of these? Similarly, notions such as 'anteriority' or 'posteriority' or even 'simultaneous' turn out to be highly problematic. What, for example, is the 'posttime' in 4? Is it the time where the gate is open, or is it the time after Reinmar's activity?

A second crucial difference relates to the way in which 'government' is described, i.e., the semantic and formal restrictions which the verb imposes on the 'filling' of its argument variables. By semantical government, I mean 'case roles' or 'thematic roles' such as agent, theme, experiences, benefactive, patient etc. I believe that these notions, whose fuzziness has often been lamented, are nothing but a gross classification of the descriptive properties which Vs may assign to an AT-pair. I see little use in such a classsification beyond an initial orientation of the 'Descriptive Component' - except it can be shown that such an assignment has clear structural consequences.. But this already relates to 'formal government', i.e., the constraints on morphological properties such as accusative, dative or syntactic properties such as 'subject, direct object'. These constraints are normally considered to be part of V's 'categorial' information. It would be much more elegant, however, if they could be derived from the AT-structure or from the Descriptive Component. Thus, one might look for principles such as 'If an argument is described at two times, then it is realised as $\mathrm{NP}_{\mathrm{A}}$ ' or 'An argument which is assigned the property 'active' is always encoded as an $\mathrm{NP}_{\mathrm{N}}$ '. It appears unlikely that this is possible for the entire verb lexicon of a language; but it should be possible for the default case. Languages are the product of a complex historical development, and just as there are idiosyncrasies in other parts of the lexical information, we should expect them here. In the next section, I will discuss some candidates for default principles of this sort in German; they mainly relate to the AT-structure and less to the Descriptive Component of V.

\section{Some default principles of AT-structure}


In most languages, AT-structure and Descriptive Component can be clustered in one V; but it is also possible that a $\mathrm{V}$ only contains an AZ-structure and must be combined with some other element to introduce descriptive content. Accordingly, a distinction can be made between 'lexcial verbs' and 'alexical verbs' ${ }^{9}$. These will be treated separately. ${ }^{10}$

\subsection{AT-structure of alexical Vs}

In German, there are at least three verbs stems which do not provide qualitative or spatial properties. These are sei-, werd-and bleib-, as illustrated by 8:

(8) a. Die Ampel war grün.

b. Die Ampel wurde grün.

c. Die Ampel blieb grün.

All three stems have only one argument variable; sei- has one time variable, whereas I assume that werd- and bleib- have two time variables. Hence, the AT-structure of sei-is simply $<\mathrm{A}, \mathrm{t}_{\mathrm{i}}$ $>$, and the AT-structure of werd- and bleib-<A, $t_{i}>\&<A, t_{j}>$, with $t_{j}$ after $t_{i}$. The difference between werd- and bleib- is that the property assigned to $A$ at $t_{i}$ and $t_{j}$ must be different in the case of werd-, whereas it must be the same in the case of bleib-. This property itself is not provided by $\mathrm{V}$ but by the word grün. In $8 \mathrm{a}$, it is the only property assigned to the street light; in $8 \mathrm{~b}$, it is only the 'ST-property' of this argument, and in 8c, it is its FT-property as well as its ST-property.

The case of bleib-illustrates an important point. The mere intuition that the situation described by a sentence is 'homogeneous', 'static' or 'does not involve a change' is not sufficient to decide on the AT-structure of its V. In 8c, nothing changes. But in contrast to 8a, it expresses that the street light was green at some time and moreover that - perhaps against some expection to this effect - it was also green at some later time. The difference is clearly brought out by additional operations on this V. Compare, for example, $9 \mathrm{a}$ and $9 \mathrm{~b}$ :

a. Die Ampel war nicht grün.

b. Die Ampel blieb nicht grün.

In 9a, it is denied that the street light was green at same time in the past (for example the time when some car approached it). In 9b, it is not denied that it was green - it is only denied that it was green at some later time, where it could have been green, too. Hence, the negation OPERATES SELECTIVELY ON ONE PART OF THE VERB'S LEXICAL CONTENT. This is also observed for other operations, for example when a modal $\mathrm{V}$ is added, thus adding further descriptive information, as in 10:

a. Wolfram was not allowed to be here.

\footnotetext{
${ }^{9}$ In the oriental tradition of linguistics, this difference is even considered to be fundamental to syntax: there are 'verbal sentences' and 'nominal sentences', where the latter are those that don't have a verb with descriptive content (see Amirova et al. 1980: 137 - 150).

${ }^{10} \mathrm{It}$ is also possible that a $\mathrm{V}$ provides no argument slot at all but only a time slot; examples include wether verbs such as to rain, to snow. The best way to analyse their lexical content is perhaps to say that they have a AT-pair in which the argument variable is lexically closed; but other analyses are imaginable. I will not pursue this problem here.
} 
b. Wolfram was not allowed to stay here.

Whereas in $10 \mathrm{~b}$, his presence at some time in the past is interdicted, this interdiction only relates to a continuation of his presence after this time in $10 \mathrm{~b}$ - i.e., to a second time where he also could be here: only the second interval is modalised by the addition of not be allowed. Hence, the lexical content of stay here is SELECTIVELY ACCESSIBLE to further grammatical operations. These operations need a 'docking place', and this is the second time variable.

A reliable analysis of the AT-structure of a V has to consider the situations which, according to our semantic intuitions, can be partially described by it but also how this stem interacts with other components of the sentence, in particular, which parts of it are selectively accessible to morphosyntactical operations. It is clear, that V wirk- in Pythagoras wirkte in Sizilien includes many heterogeneous subintervals. The old scholar may have taught, thought, prayed, slept, eaten beans, whatever. But as far as I can tell, there is no single grammatical process which has access to these subintervals, and therefore, wirk- has only one AT-pair one argument variable, one time variable. In the terminology of Bierwisch (1989), these subintervals exist on the conceptual level but not on the semantical level. ${ }^{11}$

The three Vs sei-, werd, bleib- have only one argument variable. Are there verbs stems which are descriptively empty and which have two argument variables - two-place copulas, so to speak? I believe exactly this is the function of German hab- in constructions such as Angst/Hunger/wacklige Knie/rote Haare hab-. They assign a property to an argument at a time, and the other argument indicates this property, just as grün indicates the relevant property in $8 .^{12}$ It is difficult to say what exactly distinguishes have-properties from be-

\footnotetext{
${ }^{11}$ Vendler's famous four-fold classification illustrates the point (Vendler 1967). As most philosophers, including the Philosopher himself, he bases his classification on two criteria. The first of these are 'semantic impressions' - certain states of affairs are felt to be homogeneous, do not lead to certain identifiable results etc. The second criterion concerns the behaviour of the verb (or verb phrase) towards grammatical processes, for example adverbial modification (for two hours - in two hours) or the possibility to form a progressive. No attempt is made, however, to explain WHY different verbs show this peculiar behaviour. Since Vendler himself war primarily interested in the philosophical, rather in the linguistical, aspects of various 'time schemata', this is surely justifiable. But linguists should be able to explain these observations. If Reinmar öffnete das Portal describes an 'event' - why is it impossible to indicate the duration of this event by for two minutes, whereas in two minutes is fine? The present approach suggests a natural explanation. It was assumed above that this sentence involves three time spans $t_{i}, t_{j}, t_{k}$, two of which are incompatible (the gate's being not open and the gate's being open). If the durational adverbial for two minutes applies to the entire verb content, it is not clear to which of its several temporal intervals it applies, and it cannot apply to all of them (otherwise, it would simultaneously indicate the duration of an interval at which the door is not open, and an interval at which it is open). The problem disappears when one interval is sorted out, for example in the 'result state reading' of Reinmar opened the door for two minutes; in this case, only the duration of $t_{j}$ is indicated. I have no idea why it is impossible to address the other intervals, $t_{i}$ or $t_{k}$, selectively; but note that in 9 and 10, only the second interval is affected, too. The problem should also disappear when two homogeneous intervals are involved, as in The street light remained green for two hours - the adverbial gives the joint duration of $t_{\mathrm{i}}$ and $\mathrm{t}_{\mathrm{k}}$. Note, finally, that it is easily possible to say that some heterogenous intervals are CONTAINED in some larger interval. Thus, Reinmar closed the gate in two minutes simply gives the (minimal) interval which contains $\mathrm{t}_{\mathrm{i}}, \mathrm{t}_{\mathrm{j}}$ and $\mathrm{t}_{\mathrm{k}}$.
}

${ }^{12}$ Under the analysis suggested here, $h a b$ - is lexically empty. There is an alternative: $h a b$ - is a lexical V, which assigns the two properties 'possessor-of' and 'possessum-of'. This makes 
properties; in some cases, both constructions are possible, as in rote Haare hab- und rothaarig sei- or Hunger hab- and hungrig sei-. The difference is not bound to the forms seior hab-. It is also found in attributive constructions. Thus, unnötige Befürchtungen are worries which, at a time, are unnecessary, Neidharts Befürchtungen are the worries which Neidhart has (!) at some time. Note that it is Neidhart who has the worries, whereas it is the worries which are unnecessary. In what follows, I shall not try to enter this snake pit but simply assume that both types of property assignments exist in many, if not in all, languages and that both can be related by an empty verbal element to an argument. ${ }^{13}$

Is there a dynamic counterpart to the two-place copula hab-? I assume that bekommserves precisely this function, i.e., just as grauhaarig werd- assigns the property of being gray to the $\mathrm{NP}_{\mathrm{A}}$-argument only at the second time, graue Haare bekomm- assigns the property of having grey hair to its $\mathrm{NP}_{\mathrm{A}}$ only at the second time. Is there also a counterpart to bleib-, i.e., two time spans with identical property assignment? There are some candidates, such as behalt-, bewahr- in German, or to keep in English; but their usage in this function is very restricted.

We then have a very simple picture of Vs without descriptive content. Their ATstructure can contain one or two argument variables and one or two time variables. If there is only one argument, the relevant descriptive property can be contributed in various ways, depending on the nature of this property. If there are two arguments, one of them provides this property. This may be summed up as follows:

\section{(10)VAT-structure}
a. sei-
$<\mathrm{A}, \mathrm{t}_{\mathrm{i}}>$
b. werd-
$<\mathrm{A}, \mathrm{t}_{\mathrm{i}}>\&<\mathrm{A}, \mathrm{t}_{\mathrm{j}}>$, where property assigment must be different $\mathrm{t}^{14}$
c. bleib-
$<\mathrm{A}, \mathrm{t}_{\mathrm{i}}>\&<\mathrm{A}, \mathrm{t}_{\mathrm{j}}>$, where property assigment must be identical ${ }^{15}$

only sense if these two properties are interpreted in a very abstract sense. In Wolfram hatte Hunger, we would not say that Wolfram is the possessor of the hunger. Hence, the descriptive content is close to nothing, and it is perhaps somewhat arbitrary whether one considers $h a b$ - to be alexical or lexical. The problem is largely due to the fact that alexical Vs normally go back historically to verbs with descriptive content, such as the notion of existence in the case of $s e i$-, or the notion of possession in the case of hab-. Traces of this meaning may be maintained. In the case of sei-, this is somewhat exceptional (but note the formulaic expression Es sei!), whereas it is quite palpable in the case of hab-. In any event, the AT-structure should be as described in 10 below, and if we chose the option to analyse hab- and also bekomm- as 'weak lexical verbs', instead of 'lexically empty verbs', the formulation must be changed accordingly.

${ }^{13} \mathrm{An}$ interesting borderline case between have-properties and be-properties are the usages called 'Exeption A' in section 2, such as Er bekam einen Hieb aufs Auge. In this case, one can neither say that 'he has' a hit, nor that the hit 'is' on his eye. I don't have the faintest idea how these facts should be analysed; fortunately enough, they are not central to the issue of this paper.

${ }^{14}$ There is a number of additional constraints on what can show up as relevant property expression. Thus, werd- cannot combine with expressions with spatial properties (*Er wurde im Garten, *Er wurde in den Garten), nor with qualitative properties such as offen or tot.

${ }^{15}$ It is an interesting question whether in the case of bleib-, the two time intervals (with identical property assignments) must be adjacent. Normally, this is the case. But there are some marginal cases where bleib- is possible in the sense of 'return to an earlier state', or an example in Nach diesen zwei schlimmen Monaten in New York entschloss er sich doch, in 


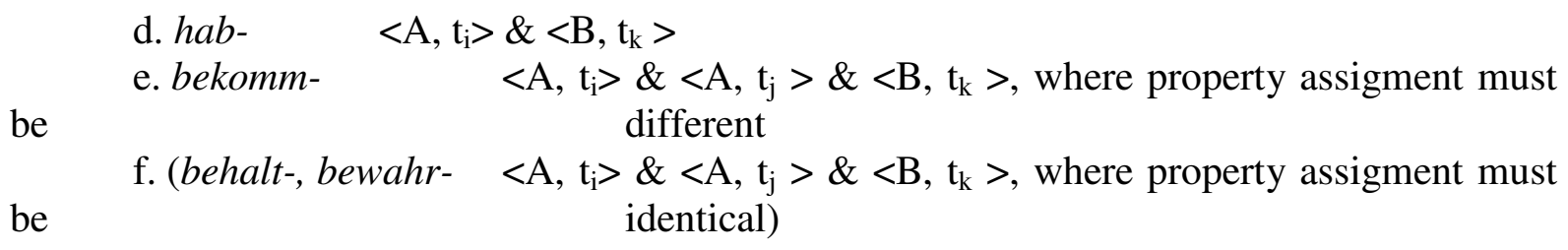

Temporal condition: $t_{j}$ after $t_{i} \& t_{k}$, where available, overlaps $t_{i}$ and $t_{j}$.

Nothing has been said so far about how the various argument variables are satisfied (if this is not left to context). If there is only one such slot, it is filled by a $\mathrm{NP}_{\mathrm{N}} \cdot{ }^{16}$ If there are two argument variables, then the asymmetry between them must be used. There are two sources of asymmetry:

(a) One argument is specified for one time span, the other argument is specified for two time spans ('temporal asymmetry').

(b) Since a property is assigned to some entity, there must be an argument which expresses the property, and another argument, which expresses the entity to which the property is assigned ('property asymmetry').

An inspection of sentences based on Vs in 10 rapidly reveals that German can most easily be described in terms of the 'property asymmetry': Er hatte einen Schnupfen/bekam einen Schnupfen, and not *Ihn hatte ein Schnupfen/bekam ein Schnupfen. We may thereforestate the following two default principles:

\section{Default Principles for alexical verbs}

DP I : If there is only one argument variable, it is filled by a $\mathrm{NP}_{\mathrm{N}}$.

DP II: If there are two argument variables, the property argument is realised as $\mathrm{NP}_{\mathrm{A}}$, whereas the other argument is realised as $\mathrm{NP}_{\mathrm{N}} \cdot{ }^{17}$

Note that in 11, conventional but very ill-defined notions such as 'subject', 'direct object' etc. play no role. If this line of thought can be substantiated, then these notions become superfluous.

\subsection{AT-Structure of lexical verbs}

If there is only one argument variable, then one or two time variables may be associated with

Paris zu bleiben. Here, he has left Paris in a way, but in another way, he has stayed. Similarly, in Die Uhr blieb stehen, one might argue that this is the clock's return to its default state. In any case, these usages are atypical.

${ }^{16}$ This is independent of whether there are one or two time variables for this argument - a point to which I will return below.

${ }^{17}$ Since $\mathrm{V}$ is alexical, it does not assign any descriptive property to this second argument at a certain time. Hence, is is a bit meaningless to provide a special time variable for this AT-pair. But this assumption does no harm, it is more general, and moreover, descriptive properties can be assigned to the argument from other sources, for example the complements in bekomm-constructions. 
it. The first case is represented by verbs stems such schlaf-, the second case by Vs such as einschlaf-, aufwach-. In both cases, the argument slot is filled by an $\mathrm{NP}_{\mathrm{N}}$ (or left to context). There are a few exceptions to this rule, such as mich hungert; they must be individually marked in the lexicon. Hence, we have a very simple default principle:

\section{Default Principles for lexical Vs}

DP III: If there is only one argument variable, it is filled by $\mathrm{NP}_{\mathrm{N}}$.

The situation is much more complicated, if there are two argument slots. Then, three constellations are possible: (a) each of the arguments is coupled with two time variables, (b) each of them is coupled with one time variable, or (c) one of the arguments has one time variable and the other argument has two. I do not know a clear example of (a) in German. Pattern (c) is clearly exemplified by stems such as öffn-, abstell- or entlass-, which involve a 'change of state' of one argument; whereas the middle pattern is exemplified by Vs such as enthalt- or gehör-, as in Apfelsaft enthält Alkohol or Mir gehört der Apfelsaft, which give the impression of describing a completely homogeneous situation. This would lead to ATstructures and descriptive properties roughly as follows $(\mathbf{P}, \mathbf{Q}, \mathbf{R}, \ldots$ are spatial or qualitative properties):

$$
\text { V AT-structure and descriptive properties }
$$

$$
\begin{array}{cl}
\underset{\text { offn- }}{\text { overlaps } \mathrm{t}_{\mathrm{i}}} & \mathbf{P}<\mathrm{A}, \mathrm{t}_{\mathrm{i}}>\& \mathbf{Q}<\mathrm{A}, \mathrm{t}_{\mathrm{j}}>\& \mathbf{R}<\mathrm{B}, \mathrm{t}_{\mathrm{k}}>\text {, where } \mathrm{t}_{\mathrm{j}} \text { is after } \mathrm{t}_{\mathrm{i}} \text { and } \mathrm{t}_{\mathrm{k}} \\
\text { gehör- } & \mathbf{P}<\mathrm{A}, \mathrm{t}_{\mathrm{i}}>\& \mathbf{Q}<\mathrm{B}, \mathrm{t}_{\mathrm{i}}>
\end{array}
$$

As was argued above, semantic intuitions alone do not suffice to decide whether die ATstructure contains one or two temporal variables. As the case of bleib-has illustrated, it may well be that there is no change in the property which the lexical content assigns an argument but that there are still good reasons to posit two time slots for it, and vice versa. We must check morphosyntactical operations that may selectively address part of the lexical content.

Such an operation is the formation of the 'past participle' PART. I will call this operation GE-; it turns Vs such as schlaf-, öffn-, abstell-, gehör- into the forms geschlafen, geöffnet, abgestellt, gehört. The way in which the attachment of GE- affects the phonological information is complex but well studied. The change in categorial information is somewhat less clear, some operations applicable to $\mathrm{V}$ are now blocked, for example, PART cannot be made finite except some other V is attached. How does GE- affect the semantical information provided by V? Under the present approach, it changes its AT-structure and possibly adds further descriptive properties. I assume that the latter is not the case but that GE- only operates on the AT-structure as follows:

(14) PART denotes ST-properties of V. ${ }^{18}$

${ }^{18}$ This formulation is admittedly somewhat sloppy, since the FT-properties are in a way present, too, in the participle; but they are not relevant for the way in which the participle is 
If $\mathrm{V}$ does not provide any ST-properties, because there is no appropriate AT-pair specified for two times, then the participle can still be formed; but when attached to an argument, it is not interpretable. This is the case for Vs such as schlaf- or gehör-; therefore, das geschlafene Kind or der (mir) gehörte Apfelsaft should not make sense, and so it is. A stem such as einschlaf-, by contrast, does have two time slots for its single argument, and therefore, das eingeschlafene Kind should be possible, and so it is. The stem öffn- has two time slots only for one of its arguments, and therefore, das geöffnete Tor assigns the SL-properties (being open) of this argument variable to the gate.

related to its argument. It would be more accurate to say that only the ST-properties of the underlying $\mathrm{V}$ are relevant for temporal synchronisation. 
There are verbs with two arguments which, intuively speaking, do not assign different properties to any argument but still lead to interpretable attributive constructions, such as lieb- or beobacht-: ein geliebtes Kind or ein beobachtetes Haus are possible. Hence, we should assume that these verbs do have two time slots for one of their arguments, although the properties assigned to this argument remain the same, just as in the case of bleib-and its single argument. ${ }^{19}$

If this is correct, then we get two very simple default principles for Vs with two arguments.:

Default Principles for lexical Vs, continued.

DP IV: If there are two arguments variables and one of these has two time slots, then this one

is filled by an $\mathrm{NP}_{\mathrm{A}}$, whereas the other one is filled by an $\mathrm{NP}_{\mathrm{N}}$.

DP V: If there are two argument variables with one time slot each, then one of them is filled by an $\mathrm{NP}_{\mathrm{N}}$ and the other one by an $\mathrm{NP}_{\mathrm{D}}$.

These are default principles, and as usual, one would expect a few exceptions, to be listed individually in the lexicon. ${ }^{20}$ But there is also a clear gap in DP V: Which of the two arguments is realised as $\mathrm{NP}_{\mathrm{N}}$, and which one as $\mathrm{NP}_{\mathrm{D}}$ ? Where does the asymmetry between Ich folge Eva and Mir folgt Eva come from? It cannot be rooted in the AT-structure; hence, it must stem from the Descriptive Component. It is not clear whether there is a general default principle which would account for why, for example, the follower, and not the followee, is realised as $\mathrm{NP}_{\mathrm{N}}$. A good candidate is DP VI:

Default Principles for lexical Vs, continued:

DP VI: If an argument is assigned the property 'active', then it is realised as $\mathrm{NP}_{\mathrm{N}}$.

As anything that is based on descriptive properties, this principle is somewhat fuzzy, and there may be alternative formulations. ${ }^{21}$ But in one way or another, it seems operative in many

\footnotetext{
${ }^{19}$ Under this analysis, attributive usage of PART is only possible if this participle has an appropriate AT-slot, because the argument needs a 'docking place'. This does not exclude other restrictions. Thus, one can say Alkuin traf eine alte Bekannte, but not eine getroffene alte Bekannte. If there is an 'inner object', then attributive usage is sometimes possible, as in ein gut gekämpfter Kampf, and sometimes not, as in ein schwer gestorbener Tod. This is partly due to the 'contrastive potential' of the participle (see Klein 2000, section 6); thus, some attributive cases are much better if an adverbial or some bother complement is added to the participle (cf. 'eine umgebene Burg and eine von Feinden umgebene Burg). But this is surely not the only criterion. Note that English is much more restricted in this regard.

${ }^{20}$ The clearest exception to DP IV are constructions in which one of the arguments expresses a measure, as in Das Buch kostet zehn Taler, Der Koloss von Rhodos wog 80 Tonnen. They do not form PART (and give the impression of being completely static), but have an $\mathrm{NP}_{\mathrm{A}}$ instead of an $\mathrm{NP}_{\mathrm{D}}$. Similarly, folg-is not the clearest case for DP V; some speakers would tolerate die von einer großen Menschenmenge gefolgte Karosse. The first sentence of Madame Bovary, Nous étions à l'étude quand le proviseur entra, suivi d'un nouveau habillé en bourgeois could well be translated gefolgt von einem Neuen, der ...
}

${ }^{21}$ See, for example, the 'Controller Constraint' which Klein and Perdue (1997) found to be of crucial importance in the utterance structure of second language learners. In a stage where learners do not have case marking, the asymmetry between arguments is either based on 
cases. Thus, one would clearly say that in Hans folgte Eva, Hans half Eva, it is Hans who is 'active' or at least 'more active' than Eva. But there are two cases where DP VI fails. First, it may be that there is simply no asymmetry in descriptive properties, as in the case of ähnel-, gleich-. Here, the choice between what is realised as $\mathrm{NP}_{\mathrm{N}}$ and as $\mathrm{NP}_{\mathrm{D}}$ is simply arbitrary. The fact that there is still a difference between Du ähnelst ihm and Er ähnelt dir result from the fact that one of the arguments has 'topic status'. It has nothing to do with the descriptive properties which $\mathrm{V}$ assigns to the two arguments (see also the discussion in section 6). The other exception concerns stems such as ziem- where we indeed have a descriptive asymmetry. It is the $\mathrm{NP}_{\mathrm{D}}$-referent who is under modest moral pressure in Das ziemt dir nicht. I see no principled reason why this is so; it seems a mere idiosyncrasy and must be booked as such in the lexical entry.

Summing up, and barring some idiosyncrasies, the picture for lexical Vs seems quite simple, too. If there is only one argument slot, it is filled by an $\mathrm{NP}_{\mathrm{N}} \cdot{ }^{22}$ If there are two argument variables, then their filling depends on whether one of them is specified for two times; this one is realised as $\mathrm{NP}_{\mathrm{A}}$, the other one as $\mathrm{NP}_{\mathrm{N}}$. If both are coupled with only one time variable, then they are realised as $\mathrm{NP}_{\mathrm{N}}$ and $\mathrm{NP}_{\mathrm{D}}$, respectively, and a potential asymmetry must be based on the descriptive properties, such as being active.

Let us turn now to those Vs whose AT-structure has three argument slots. Since in principle each of those can be coupled with one or two time slots, four constellations are possible:

(a) all arguments for one time,

(b) all arguments for two times,

(c) one argument for two times and two arguments for one time, and finally

(d) two arguments for one time and one argument for two times.

As a rule, the three arguments are realised as $\mathrm{NP}_{\mathrm{N}}, \mathrm{NP}_{\mathrm{A}}$ and $\mathrm{NP}_{\mathrm{D}}$, respectively, as in Hartmann schenkte Bligger einen Taler oder Hartmann stahl Bligger einen Taler. I shall assume that the default principles IV - VI apply here, as well. This means that as a rule, there is only one argument with two time slots, realised as $\mathrm{NP}_{\mathrm{A}}$, and two arguments with one time slot, realised as $\mathrm{NP}_{\mathrm{N}}$ and $\mathrm{NP}_{\mathrm{A}}$; the asymmetry between these is based on agentivity. The underlying structure of $\mathrm{V}$ is as follows:

$$
\text { V AT-structure and descriptive properties }
$$

schenk-, stehl- $\mathbf{P}<\mathrm{A}, \mathrm{t}_{\mathrm{i}}>\& \mathbf{Q}<\mathrm{A}, \mathrm{t}_{\mathrm{j}}>\& \mathbf{R}<\mathrm{B}, \mathrm{t}_{\mathrm{k}}>\& \mathbf{S}<\mathrm{C}, \mathrm{t}_{\mathrm{l}}>$

The temporal synchronisation between the four time variables is not straightforward. Consider Hartmann stahl Bligger einen Taler. Suppose $\mathbf{S}$ is the descriptive property 'active'. Then, $\mathrm{C}$ is filled by an $\mathrm{NP}_{\mathrm{N}}$ (Hartmann in the examples), and $\mathrm{B}$ is filled by an $\mathrm{NP}_{\mathrm{D}}$ (Bligger); $t_{1}$, the time span during which Hartmann is active, must overlap $t_{i}$, the time where the dollar is not stolen; the interval $t_{i}$ must precede the interval $t_{j}$, the time where the dollar is stolen; it is irrelevant whether $t_{1}$ also overlaps $t_{j}$. But how is $t_{k}$, the time associated with the dative

information structure or on the 'control asymmetry': the referent who has most control over the situation comes first.

${ }^{22}$ There are some interesting but altogether minor complications. Thus, if the single argument is specified twice, then it may be realised by $\mathrm{NP}_{\mathrm{N}}$ and an additional 'reflexive', as in Das Portal öffnete sich, whereas in other cases, only the $\mathrm{NP}_{\mathrm{N}}$ is found, as in Das Glas zerbrach. Again, this seems to be an idiosyncratic property of Vs. 
argument, related to ti, $t_{j}$ and $t_{k}$ ? Apparently, Bligger first has the dollar, and then, he does not have it. Thus, $t_{k}$ is in itself heterogeneous: it has two subintervals which are parallel to $t_{i}$ and $t_{j}$, respectively. But I don't know of any grammatical process which has access to theses subintervals; hence, unless evidence to the opposite is found, this distinction is on a purely conceptual level. It is clearly felt, but it is blind for grammatical processes, and there is no reason to reserve two time variables for this argument in the lexical entry. All we can say is that $t_{k}$ must overlap $t_{i}$ as well as $t_{j}$, and it is the switch from $t_{j}$ to $t_{k}$ which induces the subdivision within $\mathrm{t}_{\mathrm{k}}$. Other Vs with three arguments, such as erzähl-, do not have such a split within the time slot associated with their $\mathrm{NP}_{\mathrm{D}}$.

I will conclude this section with two observations, one of which fits the emerging picture quite well, whereas the other one disturbs it. In German, there is a number of verbs such as passier-, widerfahr-and similar ones, which somehow lead to the impression that the 'subject' has the wrong case: Ihm ist ein Unglück widerfahren/ein Fehler unterlaufen. The fact that their PART allows attributive use (das ihm widerfahrende Unglück/der ihm unterlaufene Fehler) demonstrates that against the default, a 'two-times argument' is realised as $\mathrm{NP}_{\mathrm{N}}$, rather than as $\mathrm{NP}_{\mathrm{A}}$; the 'one-time argument' is realised as $\mathrm{NP}_{\mathrm{D}}$. As a consequence, case marking and agreement mark ein Unglück, ein Fehler as 'subject', whereas the 'time variable status' marks ihm as the 'subject'. Thus, the ambivalent impression of these constructions finds a natural explanation. The problematic observation concerns the fact that bekomm-, though it involves two time variables, does not allow attributive use of its PART. As was noted in footnote 16, the mere presence of an appropriate AT-pair does not guarantee this; there may be other constraints; but in this case, it is not easy to see what such a constraint could be. ${ }^{23}$

\subsection{Summary}

In this section, we successively introduced a number of default principles which determine the 'filling' of argument variables. These were:

\section{Default Principles for the filling of argument variables, first version}

DP I : If there is only one argument variable, it is filled by a $\mathrm{NP}_{\mathrm{N}}$.

DP II : If there are two argument variables, the property argument is realised as $\mathrm{NP}_{\mathrm{A}}$, the other argument is realised as $\mathrm{NP}_{\mathrm{N}}$.

DP III: If there is only one argument variable, it is filled by $\mathrm{NP}_{\mathrm{N}}$.

DP IV: If there are two argument variables and one of these has two time slots, then this one is filled by an $\mathrm{NP}_{\mathrm{A}}$, whereas the other one is filled by an $\mathrm{NP}_{\mathrm{N}}$.

DP V : If there are two argument variables, both only with one time slot, then one of them is filled by an $\mathrm{NP}_{\mathrm{N}}$ and the other one by an $\mathrm{NP}_{\mathrm{D}}$.

DP VI: If an argument is assigned the property 'active', then it is realised as $\mathrm{NP}_{\mathrm{N}}$.

I and II apply to alexical verbs, III - VI apply to lexical verbs.

These formulations are partly redundant ( $\mathrm{A}$ is the same as $\mathrm{C}$ ); moreover, the way in which the

\footnotetext{
${ }^{23}$ One - quite speculative - possibility is this. Suppose we assign two time variables to both arguments of bekomm-. This would be in agreement with DP III, according to which (lexical) Vs encoded by $\mathrm{NP}_{\mathrm{A}}$ have two times. Then, it is not defined to which argument the PART of bekomm- relates, and therefore, its attributive use is odd.
} 
principles are stated here does not cover Vs with three argument slots. We will therefore try to revise them.

It seems clear, first, that one argument variable must be filled by an $\mathrm{NP}_{\mathrm{N}}$. Exceptions are rare. If there is only one argument, this rule is sufficient. If there are more, then the differences noted in either AT-structure or Descriptive Component come into play. As for the former, the only difference is whether an argument variable is coupled with one or with two time variables. In the former case, it is realised as $\mathrm{NP}_{\mathrm{D}}$, and in the latter, as $\mathrm{NP}_{\mathrm{A}}$. Again, exceptions are rare. But problems arise if there is only one argument. Then, the requirement to mark this argument $\mathrm{NP}_{\mathrm{N}}$ is at variance with the requirement to realise it as $\mathrm{NP}_{\mathrm{A}}$ (if it is a 'two-times argument') or as $\mathrm{NP}_{\mathrm{D}}$ (if it is a 'one-time argument'). In German, the $\mathrm{NP}_{\mathrm{N}^{-}}$ principle DP I clearly wins this competition. It is, so to speak, the default of defaults. Different problems arise if there is more than one argument variable with identical time variables. Then, the other source of asymmetries, the Descriptive Component, comes into play. This can happen in two ways: either $\mathrm{V}$ assigns some property to some argument which is decisive. One such possibility is considered here - the property of being 'active'. Or V itself is lexically empty, and one argument is used to express the descriptive property. Hence, we have the following revised default principles:

(19) Default Principles for the Filling of argument variables, revised version

DP A One argument variable is filled by an $\mathrm{NP}_{\mathrm{N}}$.

DP B Two-times argument variables are filled with $\mathrm{NP}_{\mathrm{A}}$.

$\mathrm{DP} C$ One time-argument variables are filled with $\mathrm{NP}_{\mathrm{D}}$

DP D If $\mathrm{V}$ assigns the property 'active' to an argument, then this argument is realised as $\mathrm{NP}_{\mathrm{N}}$.

DP E If $\mathrm{V}$ is lexically empty, then the argument which expresses the descriptive property is realised as $\mathrm{NP}_{\mathrm{A}}$.

In cases of conflict, DP A is strongest.

These default principles are relatively simple, and they seem to cover the vast majority of cases.They confine lexical information to what is indispensable, and they avoid firmly established but completely ill-defined concepts such as 'subject', 'direct object' and similar ones.

It has often been noted (see, e.g., Reis 1982, Keenan 1976) that what is called 'subject' is actually a peculiar cluster of heterogenous features - morphological features such as case marking, syntactical features such as position, semantical features such as agentivity, and pragmatical features such as topic status; these may but need not be present. In other words - this notion is a cloud. This is in no way different for 'direct object'. How is it defined? In school grammar, no definition is given at all; normally, these notions are illustrated by examples, and the relevant generalisations are left to the reader. Modern apporaches, lest they simply continue this tradition, define them either in terms of case roles, such as 'theme, benefactive, patient', etc., or in terms of tree geometry. ${ }^{24}$ The first way is

\footnotetext{
${ }^{24}$ Recently, a number of linguists, in particular Manfred Bierwisch, Paul Kiparsky and Dieter Wunderlich, developed an analysis of this problem which also strongly deviates from the tradition. Details vary; here, I follow Wunderlich (1996). In this approach, the asymmetry of argument variables is defined by the features 'higher role available (in the same clause)' 'lower role available'. Consider, for example, the sentence Er schenkte es ihr. The variable filled by es is assigned the feature complex 'higher role available, no lower role available',
} 
unsatisfactory because these notions themselves are most unclear - a fact that has often been deplored (see the extensive discussion in Helbig 1973). Moreover, they do not make sense in many cases. It may be justified to call the $\mathrm{NP}_{\mathrm{D}}$ a 'benefactive' in Er half ihr, but surely not in Errötend folgt er ihren Spuren. The tree geometry approach, generally used in Generative Grammar, looks much clearer. One might say, for example: 'The direct object is the first NP immediately dominated by V on D-structure.' (This is the definition in Chomsky 1965, where this idea was first worked out, the argument is analogous for other variants of generative grammar). But in fact, such a solution only shifts tte problem to the question WHY A PARTICULAR TREE STRUCTURE IS ASSUMED IN A SPECIFIC CASE. It is not the Lord who places einen Apfel immediately under $\mathrm{V}$ in Adam aß einen Apfel but the linguist. Trees, as this term is used in linguistics, are abstract structures based on two types of structural relations between its elements - dominance and precedence. These, and only these, relations are available to represent the structural relationship between simple or complex expressions. It is the linguist's task to decide why certain elements are connected to each other by a vertical stroke, i.e., by a dominance relation, and why a certain element is placed in the tree such that it precedes some other element. Very often, the two relations available turn out to be insufficient, and the linguist's way out is usually to stipulate various trees, together with mechanisms to relate these to each other ('transformations', 'reanalysis', and other ones). In any case, it is not the tree which says why something is connected to something else in a particular way - why, for example, an NP is in the 'direct object relation' to a V. It is the linguist who constructs the tree in a given case, and this decision must be based on clear and reasonable criteria.

Let me conclude this section with a glance at two closely related phenomena that have found considerable attention in typology as well as in structural linguistics - the distinction between 'ergative' and 'accusative' languages and the distinction between 'unergative' and 'unaccusative' verbs. Crucial to the approach developed here is the distinction between what one might call 'one-time arguments' and 'two-times arguments'. In German, the former can be realised by $\mathrm{NP}_{\mathrm{D}}$, the latter can be realised by $\mathrm{NP}_{\mathrm{A}}$, whereas $\mathrm{NP}_{\mathrm{N}}$ is ambivalent in this regard. In sentences with two arguments, $\mathrm{NP}_{\mathrm{N}}$ expresses the one-time argument, thus leaving, in the default, the two-times argument to $\mathrm{NP}_{\mathrm{A}}$. But how about sentences with only one argument? It can be 'one-time', as in the case of schlaf-, and it can be 'two-times', as in

the variable which is filled by er gets assigned the feature complex 'no higher role available, lower role available', and finally, the third variable, which corresponds to $i h r$ gets assigned 'higher role available, lower role available.' Morphological case marking is then easily defined on the basis of such a feature complex, i.e., 'no higher role available, lower role available' is marked by nominative in German. This is very elegant; but it raises two basic problems. First, which independent criteria are crucial to decide why some element is 'higher' than some other element? They cannot be based on morphological marking, because this would render the analysis circular. Are they based on case roles - say 'benefactive' is lower than 'agent' but higher than 'theme'? Then, we are back to the familiar problems with these notions. Or do they exploit the depth of embedding in lexical decomposition? But how would this work for verbs such as beobacht-, which are not assumed to be lexically decomposable? - Second, I do not see how this analysis works for Vs with $\mathrm{NP}_{\mathrm{N}}$ and $\mathrm{NP}_{\mathrm{D}}$ alone, such as helf-, ziem- or ähnel-? In Wunderlich (1997), this case is analysed as a lexically marked deviation from the case assignment dictated by the 'role hierarchy'. This is surely not false; but it is not satisfactory, either. After all, there must be a reason why it is possible to say die von uns Flüchtlinge, but not die von uns geholfenen Flüchtlinge. In other words, this deviation is not just an idiosyncrasy of case marking. The lexical content must contain some feature which predicts this fact as well as the peculiar case marking. 
einschlaf-. How is it marked - by the 'one-time case' nominative, or by the 'two-times case' accusative, or does this vary, depending on whether the argument itself is paired with only one time variable, as in schlaf-, or with two, as in einschlaf-? In fact, all of these possibilities are found in the languages of the world. The first possibility leads to an 'accusative language'. The second possibility leads to an 'ergative language', and the third case exemplifies the most important type of 'split ergativity'- the type in which the marking depends on 'aspect'. Consider now a language in which the first option is chosen, such as German. Then, the case of the single argument is in a way ambiguous. It may act as a 'twotimes case', i.e., the 'subject of an intransitive verb' corresponds in this regard to the 'direct object of a transitive verb'. If, however, it functions as a 'one-time case', i.e., the 'subject of an intransitive verb' corresponds to the 'subject of a transitive verb'. This naturally explains most characteristic properties of the familiar distinction between 'unaccusative' (or 'ergative') and 'unergative' verbs, introduced by David Perlmutter in the early Seventies and then intensively discussed in the generative tradition (see, for example, Grewendorf 1989), for example the choice of auxiliaries or the behaviour towards passivisation.

In the present approach, the 'passive flavour' of ergative verbs as well as of bekommis due to the fact that the $\mathrm{NP}_{\mathrm{N}}$, rather than a $\mathrm{NP}_{\mathrm{A}}$, fills an argument variable with two time intervals. Thus, the common relation between 'patient' and 'change-of-state' (see, for example, Dowty 1991) is reverted.

\section{5. bekomm- and the synchronisation of AT-structures}

Let us now see how the present approach analyses the various constructions based on bekomm-, as discussed in section 2. Essential to this analysis is the idea that bekomm-always makes the same contribution to the entire meaning. It says that $\mathrm{NP}_{\mathrm{N}}$ is specified at two times: first, it does not have the property expressed by $\mathrm{NP}_{\mathrm{A}}$, and then, it has it. Property assignments to $\mathrm{NP}_{\mathrm{A}}$ may also change; this depends on the nature of the complement.

In order to get from the bare stem bekomm- to full constructions such as Gottfried bekam einen Schlips, Gottfried bekam einen Schlips um den Hals or Gottfried bekam einen Schlips gebügelt, several morphosyntactical operations are necessary. These can be divided into four groups:

(a) morphological operations on bekomm- (and possibly other verb stems);

(b) 'synchronisation' of various AT-structures, if more than one is involved;

(c) 'filling' of the variables;

(d) all elements must be ordered, if there is a choice.

The third point was already discussed for the 'argument variables' in the preceding section. The 'filling' of time variables is often left to context. But they can also be made explicit, for example by temporal adverbials. This is a complicated issue, which is not central to our present concern, so, I will not follow it up here.

I take it that grammar consists of a set of elementary expressions, the lexemes, and a set of operations which turn simple expressions into more complex ones. In other words, a grammar is an algebra. A lexeme is a bundle of three types of information - phonological, categorial, semantical. Phonological and semantical information may be absent in special cases. Operations are conveniently divided into two groups - morphological operations, which operate within the word, and syntactical operations, which combine words; there are some borderline cases, which need not concern us here. Common to all operations is the fact that they normally change, and sometimes maintain, phonological, categorial and semantical information in a characteristic way. I do not think that any of these assumptions is particularly controversal. 


\subsection{Morphological operations on the word stem}

Ever since the Greek grammarians, a distinction has been made between 'verba finita' and 'verba infinita'. This distinction is firmly established; but no one really knows what the notion 'finiteness', present in some forms and absent in others, really means; we will come back to this question in a moment. It is clear, however, that a bare V such as schlaf- is neither the one nor the other. It is only made 'finite' or 'infinite' by certain morphological operations. I will assume that German has five such operators. These are (I illustrate their function for the third person singular in the first two cases):

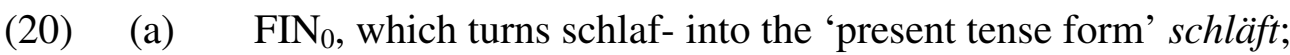

(b) $\quad \mathrm{FIN}<$, which turns schlaf- into the 'preterite tense form' schlief;

(c) -EN, which turns schlaf- into the (bare) infinitive schlafen;

(d) -END, which turns schlaf- into the 'present participle' schlafend;

(e) GE-, which turns schlaf- into geschlafen.

In what follows, we will not consider the present participle, and we will ignore other inflectional variants of the finite forms.

All of these operators somehow modify the phonological, categorial and semantical features of $\mathrm{V}$ to which they apply. The phonological effects are sometimes complex, but wellstudied, and will not be discussed here. It is much less clear how categorial and semantical properties are affected. Let me begin with $\mathrm{FIN}_{0}$ and $\mathrm{FIN}<$.

The sentences Hagen bekommt graue Haare and Hagen bekam graue Haare only differ with respect to their finiteness marking: the former has $\mathrm{FIN}_{0}$, the latter FIN $<$. I shall say that they have the same 'sentence basis'. A sentence basis consists (minimally) of a V and an appropriate filling of its argument variables. In this example, the sentence basis is [Hagen bekomm- graue Haare]. In German, a sentence basis cannot survive as an independent construction; it must be made finite by attaching either $\mathrm{FIN}_{0}$ or $\mathrm{FIN}<$ to $\mathrm{V}$. What is the function of this process? This is best illustrated by focussing on just the finite verb, as in

\section{(21) Hagen BEKAM graue Haare.}

This focus can mark two types of contrast. It can highlight the fact that whatever is described by the sentence basis applies to some time in the past, and not, for example, right now. It can also highlight the fact that such an assertion is made - in contrast to the possibility that the opposite assertion is made OR to the possibility that this is entirely open. Thus, 21 may be used to contradict an earlier assertion such as Hagen bekam keine grauen Haare, but also in order to conclude a discussion whether he got grey hair or not. In both cases, the information contained in the sentence basis is clear; what is at stake is only whether it is asserted or not. Note that we do not have a contrast here between 'true' and 'false', but between 'asserted' and 'not asserted'. Hence, the function of finiteness marking is not just temporal. It indicates that for some time $t_{i}$ which includes the utterance time $\left(\mathrm{FIN}_{0}\right)$ or which precedes the utterance time $(\mathrm{FIN}<)$, it is asserted that $t_{i}$ has the properties described by the sentence basis. This time $t_{i}$ will be called here 'topic time'. It must somehow be related to the time spans inherent to the sentence basis, thus characterising these time spans as 'asserted times'. Thus, a sentence such as Hagen bekam graue Haare is true if some time $t_{i}$ in the past includes a time $t_{j}$, at which Hagen did not have grey hair, and a later time $t_{k}$, at which he did have grey hair. Finiteness marking is just a special case of what we have called 'synchronisation' - it synchronises the 
topic time, i.e., the time to which the assertion is restricted, with one or several of the time spans contained in the sentence basis.

Let us turn now to the 'non-finite' markings GE- and -EN. Their first effect is to block the attachment of $\mathrm{FIN}_{0}$ or $\mathrm{FIN}<$. It is no longer possible to turn a sentence basis into a full sentence, which expresses an assertion - unless another $\mathrm{V}$ is attached (this will be discussed in the next section). They also affect the AT-structure of V. As was argued in section 4.2, GEselects the SL-properties of V and assigns them to the argument with which it is combined. Thus, ein eingeschlafener Hund is a dog with the SL-properties of einschlaf-; ein gebügeltes Hemd is a shirt with the SL-properties of bügel-, i.e., it is more or less smooth. ${ }^{25} \mathrm{~A} \mathrm{~V}$ such as schlaf- has only one AT-pair, hence no argument variable with a second time, and therefore, ein geschlafener Hund is not interpretable. If there are two argument variables in $\mathrm{V}$, then the one with only one time is no longer subject to the default principles of argument filling, as described in 20. This does not mean that it cannot be specified at all; the mechanisms are much the same as those which fill the time variables, i.e., an optional adverbial phrase must be used (von Volker gestern gebügeltes Hemd). - If V is subject to -EN, i.e., if it is turned into an infinitive, then the argument filling according to DP A is blocked, i.e., an argument variable which would be realised by an $\mathrm{NP}_{\mathrm{N}}$ cannot be filled; otherwise, the AT-structure remains unaffected.

\subsection{Syntactic operations on V}

When GE- or -EN has been applied to a V, it is no longer possible to construct a sentence basis directly. First, another $\mathrm{V}$ has to be syntactically attached, resulting in structures such as schlafen woll-, beten geh- or eingeschlafen sei-. There are numerous restrictions to these combinations, not to be discussed here. In each case, the relevant AT-structures are 'synchronised'. This means, that their ARGUMENT variables are partly equated - a process that has been extensively studied in the linguistic literature under the label of 'control'. By contrast, the way in which their TIME variables are related to each other has found little attention. We consider some illustrative examples. In the case of beten geh-, both Vs have only one AT-pair each, say $<\mathrm{A}, \mathrm{t}_{\mathrm{i}}>$ for $g e h$ - and $\left.<\mathrm{B}, \mathrm{t} \mathrm{j}\right\rangle$ for beten. The argument variable is equated, and $\mathrm{t}_{\mathrm{i}}$ must precede $\mathrm{t} \mathrm{j}$. The situation is more difficult with schlafen woll-. Here, the time of woll- may precede the time of schlaf-; but it is not excluded, of course, that someone wants what he is just doing; hence, the two time may also overlap. In the case of eingeschlafen sei-, the underlying $\mathrm{V}$ provides two time variables for its single argument, whereas sei- has only one; but the GE- marking selects the properties of the second time, hence, it is this time which is identified with the single variable of sei-. In all of these cases, one of the two AT-structures is provided by an expression which is 'made non-finite' by operations GE- or -EN. It may also stem from an expression which is 'non-finite' to begin with, such as an adjective like glatt, or an adverbial like here or in den Keller. This now brings us back to the various construktions with bekomm-. We will discuss the various patterns in turn.

\section{3 bekomm-, $\mathrm{NP}_{\mathrm{A}}, \mathrm{NP}_{\mathrm{N}}$}

\footnotetext{
${ }^{25}$ Note that ein gebügeltes Hemd by itself does not say when the shirt has these ST-property, for example right now or at some time in the past. The fixing of the time variables inherent to gebügelt is either left to context or results from other factors, for example temporal adverbials or synchronisation with the topic time.
} 
The AT-structure of bekomm- is $<\mathrm{A}, \mathrm{t}_{\mathrm{i}}>\&<\mathrm{A}, \mathrm{t}_{\mathrm{j}}>\&<\mathrm{B}, \mathrm{t}_{\mathrm{k}}>$. Other than in the case of lexical verbs, $\mathrm{NP}_{\mathrm{N}}$ realises the 'two-times argument', whereas the other one contributes the descriptive component to the property which $\mathrm{NP}_{\mathrm{N}}$ first does not have and then has. It is this 'inverted' distribution of 'one-time argument' and 'two-times argument' which gives this construction its receptive flavour. The entire constellation of Volker bekam einen Schlips can then be depicted in the following diagram (variables are placed beneath the elements which introduces them, NPs which fill these variables are placed behind): ${ }^{26}$

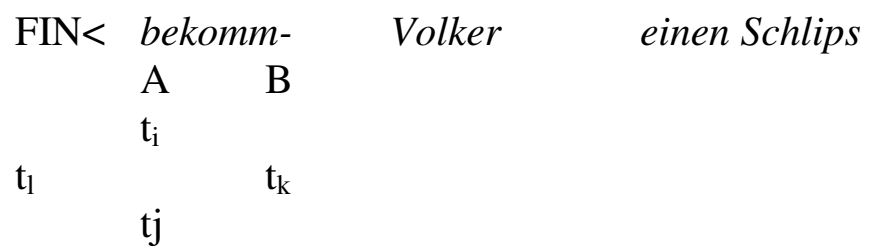

The time for which the assertion is made, $t_{1}$, precedes the time of utterance. It includes $t_{i}$ and tj, i.e., it includes first an interval at which Volker does not have a necktie, and then a time where he has. I have no clear intuition whether $t_{k}$ should also split analoguously.

\section{4 bekomm-, $\mathrm{NP}_{\mathrm{A}}, \mathrm{NP}_{\mathrm{N}}$ and a non-verbal complement}

Non-verbal complements include 'stative' expressions, such as glatt, but also 'dynamic expressions' such as in die Hand. I assume that the former have one time variable, whereas the latter have two time variables for their single argument, with opposing property assignments: being in the hand is limited to the second time. In this case, we have:

$\begin{array}{rrrrr}\text { (23) a. FIN }< & \text { bekomm- } & \text { in die Hand } & \text { Volker } & \text { einen Schlips } \\ & \mathrm{A} & \mathrm{B} & \mathrm{C} & \\ & \mathrm{t}_{\mathrm{i}} & & \mathrm{t}_{\mathrm{m}} \\ \mathrm{t}_{\mathrm{l}} & & \mathrm{t}_{\mathrm{k}} & & \\ & \mathrm{tj} & & \mathrm{t}_{\mathrm{n}} & \end{array}$

Here, the synchronisation becomes tricky. In Volker bekam einen Schlips in die Hand the necktie is first not in the hand, and then in the hand; hence, $\mathrm{C}$ is equated with $\mathrm{B}, \mathrm{t}_{\mathrm{i}}$ must be simultaneous to $t i$, and $t_{n}$ must be simultaneous to $t_{j}$. This is independent of whether the complex change of state is due to Volker's efforts (unlikely in this example) or to some other reason.

Consider now Volker bekam einen Schlips sauber - a sentence which sounds a bit odd out of context, but is not when followed, for example, by und sonst garnichts. We have:

$$
\text { b. FIN }<\text { bekomm- } \quad \text { sauber } \quad \text { Volker einen Schlips }
$$

\footnotetext{
${ }^{26}$ I assume here for simplicity's sake that FIN contributes a time variable but not an argument variable. It is very suggestive, however, to assume that it has a normal AT-pair $\left\langle A, t_{i}\right\rangle$, where $\mathrm{A}$ is the slot for the 'topic entity' and $t_{i}$ is the slot for the topic time. The variable $A$ is then equated with one of the 'lexical arguments', preferably the argument which is filled by an $\mathrm{NP}_{\mathrm{N}}$. If $\mathrm{V}$ does not provide such an argument, then the 'topic variable' must be filled by something else, for example a dummy es. We will briefly return to this point in section 6 .
} 


$\begin{array}{cccc} & \text { A } & B & C \\ & t_{i} & & \\ t_{1} & & t_{k} & t_{m}\end{array}$

The most natural reading is that Volker tried to wash something and managed to get a necktie clean. Hence, $t_{m}$ is equated with $t_{j}$, the time where he has the shirt in a state in which it is clean. But it may also have a reading, under which he simply got a necktie which was clean. Thus, it is only required that $t_{j}$ overlaps $t_{m}$. This reading seems only possible with an intonational break after einen Schlips, for example in the sequence ...bekam einen Schlips sauber - und alle anderen waren genauso dreckig wie zuvor. I have no idea how to explain this.

5.5 bekomm-, $\mathrm{NP}_{\mathrm{A}}, \mathrm{NP}_{\mathrm{N}}$ and PART

This is the classical 'Rezipientenpassiv', as in Volker bekam einen Schlips gewaschen. Under the analysis suggested here, it is only a special case with the following properties:

\begin{tabular}{ccccc} 
FIN $<$ & \multicolumn{2}{r}{ bekomm- } & \multicolumn{2}{r}{ gewaschen } \\
& $\mathrm{A}$ & $\mathrm{B}$ & $\mathrm{C}$ & $\mathrm{D}$ \\
& $\mathrm{t}_{\mathrm{i}}$ & & $\mathrm{t}_{\mathrm{m}}$ & to \\
$\mathrm{t}_{\mathrm{l}}$ & & $\mathrm{t}_{\mathrm{k}}$ & & \\
& $\mathrm{tj}$ & & $\mathrm{t}_{\mathrm{n}}$ &
\end{tabular}

Volker einen Schlips

Again, B and C are equated, and the argument which fills them, einen Schlips, is characterised at two times, $t_{m}$ and $t_{n}$; both of these overlap with $t_{k}$. More interesting, however, is the fact that $t_{m}$ and $t_{n}$ are also paralleled to $t_{i}$ and $t j$ : it is not the case that at some time, Volker gets a necktie, and at some other time, this necktie is washed - the two state changes go hand in hand. This is independent of how D is interpreted - it may be identical to B, i.e., Volker, or it may be some other person.

It is this parallel change of state with respect to the $\mathrm{NP}_{\mathrm{A}}$ which is characteristic of this construction. In Volker bekam einen gewaschenen Schlips, there must be two state changes, as well; but synchronisation is different: it is only required that $t_{n}$ (i.e., the time at which the necktie is more or less clean) must not be later than tj, i.e., the time at which Volker has it. In other words: ATTRIBUTIVE USE AND USE AS 'SECONDARY PREDICATE' DIFFER NOT ONLY IN WORD ORDER AND INFLECTION (ONLY THE FORMER IN VOLVES AGREEMENT), BUT ALSO IN THE WAY IN WHICH THE TWO AT-STRUCTURES ARE SYNCHRONISED.

\section{5 bekomm-, $\mathrm{NP}_{\mathrm{A}}, \mathrm{NP}_{\mathrm{N}}$ and $z u+$ infinitive}

This concerns examples such as Volker bekam ein Hemd zu waschen. Here, the complement does not indicate that the shirt has some particular property, but that it ought to have it at some later time. Hence, other than in all cases considered so far, the wash-times must be later than the bekomm-times, and it is not asserted that there is ever such a time - it is only possible. This, I believe, accounts for the modal character of the complement. The peculiar modal character cannot be due to the infinitival marking -EN alone; but it may result from the application of $z u$ to the bare infinitive. Apparently, this operation marks that the temporal intervals of the infinitive are, so to speak, 'target intervals', i.e., they are later than the 
intervals of the stem, with which it combines to form a construction that can be made finite. I indicate this in the following illustration by ' $<$ '. ${ }^{27}$ Hence, we have:

\begin{tabular}{|c|c|c|c|c|}
\hline $\mathrm{FIN}<$ & bek & & $z u$ & \\
\hline & A & B & & $\mathrm{C}$ \\
\hline & $\mathrm{ti}$ & & & $t_{n}$ \\
\hline $\mathrm{t}_{1}$ & $\mathrm{tj}$ & $\mathrm{t}_{\mathrm{k}}$ & $>$ & \\
\hline
\end{tabular}

Note that the 'pretime' marking relates to all intervals contributed by wasch-, in cluding the time at which someone is (possibly) active. Normally, this is the argument which fills A, here Volker. But what is really said is that during $\mathrm{t}_{1}$, Volker gets a necktie which is 'modal-washed' later.

5.6 A default principle of synchronisation

As the inspection of the various patterns has shown, synchronisation of AT-structures is subject to some variation. But there seems to be a clear default principle, which may be stated as follows:

\section{Default principle of AT-synchronisation}

AT-structures are aligned.

This means that, unless marked otherwise, all time intervals are, so to speak, in the same 'tunnel'. If two AT-structures contain only one variable each, these two variables are identified. If one of them has two variables and the other one has only one, than the latter contains the two former, thus giving rise to an internal bipartition.

There are three ways to deviate from 26. First, such a deviation may be lexically marked. Thus, Vs such as dürf-, woll- may align with the 'pretime' of the infinitive with which they combine. Second, other morphosyntactical operations may intervene. An example is the use of zu in Volker bekam einen Schlips zu waschen or Volker hat ein Buch zu lesen. Third, other constructions may be used, such as the 'attributive' combination of a participle or an 'adjective' with a noun. This accounts for the difference between Er bekam ein Hemd sauber and Er bekam ein sauberes Hemd, or Er bekam ein Hemd gewaschen and Er bekam ein gewaschenes Hemd. In German, word order and agreement discriminate between these two constructions. But these formal differences are only symptoms of differences in the temporal relationship between the various AT-structures.

\section{Concluding remarks}

\footnotetext{
${ }^{27}$ It would be elegant, of course, if $z u$ had this function in all other constructions, as well. In fact, this is often the case, for example in 'pretime verbs' such as $E r$ beabsichtigt/plant/verspricht zu kommen. But there are also many cases, where there is no such 'pretime' function associated with $z u$.
} 
I would like to end this paper with three remarks. The first concerns the transition from a 'sentence basis' to a finite sentence. A sentence basis consists minimally of some $\mathrm{V}$ and an appropriate filling of its variables. The descriptive component of $\mathrm{V}$ assigns qualitative or spatial properties to the arguments. But it does not say anything about whether this information is new or old, whether it constrasts to other information available in the context, and so on. It just provides lexical content. In a full sentence, however, this sentence basis must be integrated into the ongoing flow of information. This has numerous consequences for word order, intonation and other types of the final phonological form of the sentence.

I will not follow up this point in general but only address one particular aspect of this integration into the information flow. It concerns the 'topic status' of some parts of the sentence. A sentence basis such as [eine Tür offen sei-] is neither true nor false, it is a selective description of a kind of situations, and depending on which situation this description is applied, it is correct or not. Suppose someone says on some occasion: 'A door was open'. Is this assertion true or false? This cannot be judged unless it is clear which situation is talked about: the 'topic situation' must somehow be fixed. Accordingly, a finite sentence has a 'topic component', which minimally includes the indication of a time, a place, and a world; all of these can be made explicit in the sentence itself, but they can also be given in context. Very often, the topic component is enriched by descriptive information from the sentence basis, in particular by marking one of its arguments as 'topic entity'. Such an argument is often called 'subject'. But it should be clear that there is a difference between 'subject' as a lexically characterised element of the sentence basis ('the 'semantical subject') and 'subject' as a specific component of the information structure. These two properties may go hand in hand, and in fact, they often do. But they need not, and this has been a considerable sourse of confusion in the linguistic tradition,. Thus, 'subject' is one of these familiar notions which render a first access to the phenomena quite easy but then hamper any further progress towards an appropriate understanding of these phenomena.

The second remark concerns 'case marking', as reflected in labels such as $\mathrm{NP}_{\mathrm{N}}, \mathrm{NP}_{\mathrm{D}}$, $\mathrm{NP}_{\mathrm{A}}$. This is one of the few traditional notions used throughout this paper. In German, it is relatively clear what this case marking is: it relates to particular morphological variations of a noun stem (and perhaps other stems as well). In English, such a variation is exceptional. This means that default principles such as those in 19 do not directly apply: the marking of 'onetime argument', 'two-times argument' is different. Instead of 'realised by $\mathrm{NP}_{\mathrm{N}}$ ', we would have to say something like 'realised by the first argument which precedes V', instead of 'realised by $\mathrm{NP}_{\mathrm{A}}$ ', we would have to say something like 'realised by the argument which immediately follows V', and the like. Whether such a marking should be called 'case', as well, is merely a terminological question. It does not affect the underlying principles, which, in the default case, determine the way in which the argument slots of a V are filled.

The third remark is more general. Much of the approach presented in the preceding is sketchy and speculative. There are two reasons why it was advanced despite this fact. The first are problems with the analysis of temporality. Traditionally, it is described in terms of a few categories such a tense, aspect or Aktionsart. But these notions are by far too crude to reflect the complex internal makeup of a sentence, let alone a series of sentences. There is not just an 'event time' which is somehow related to a 'reference time' - whatever this may mean - or to 'the moment of speech'. As a rule, there are many temporal intervals, related to each other in complex ways, and very often, these are tightly linked to one particular argument. Somehow, this facct has to be accounted for. While the way in which I have tried to do this here, is no doubt very elementary, vague and perhaps false in more than one respect, I believe that the general approach is correct. - The second reason is a deep dissatisfaction with all of these 'Begriffe[n], die sich bei der Ordnung der Dinge als nützlich erwiesen haben' - notions such as 'subject, direct object, passive, tense' and the like. Over the centuries, they have been useful in giving initial, highly superficial characterisations of groups of linguistic phenomena, 
and they are still useful to this end nowadays. But that is all they are, and if we ever want to go beyond a superficial understanding of language structure, we must abandon them. 


\section{References}

Amirova, T. A., et al. 1980. Abriss der Geschichte der Linguistik. Leipzig. VEB Bibliographisches Institut.

Bierwisch, Manfred. 1989. Event nominalisations. Proposals and problems. Linguistische Studien 194. Akademie der Wissenschaften Berlin. 1-73.

Chomsky, Noam. 1965. Aspects of the theory of syntax. Cambridge, Mass. MIT Press.

Dowty, David. 1991. Thematic proto-roles and argument selection. Language 67. 547 - 619.

Eroms, Hans-Werner. 1978. Zur Konversion von Dativphrasen. Sprachwissenschaft 3. 357405.

Grewendorf, Günther. 1989. Ergativity in German. Dordrecht. Reidel.

Hume, David. 1748. An enquiry concerning human understanding. London.

Helbig, Gerhard. 1973. Die Funktionen der substantischen Kasus in der deutschen Gegenwartssprache. Halle. Niemeyer.

Jackendoff, Ray. 1990. Semantic Structures. Cambridge, Mass. MIT Press.

Keenan, Ed. 1976. Towards a universal definition of 'subject'. Charles N. Li, ed., Subject and Topic. New York. Academic Press. 303-334.

Klein, Wolfgang. 1994. Time in language. London. Routledge.

Klein, Wolfgang. 2000. An analysis of the German perfect. Language 76. 358-382.

Klein, Wolfgang und Perdue, Clive. 1989. The learner's problem of arranging words. Brian MacWhinney and Elizabeth Bates, eds. The cross-linguistic study of sentence processing. Cambridge. Cambridge University Press. 292-327.

Leirbukt, Oddleif. 1997. Untersuchungen zum bekommen-Passiv im heutigen Deutsch. Tübingen. Niemeyer.

Lenz, Barbara. 1995. un-Affigierung: unrealisierbare Argumente, unausweichliche Fragen, nicht unplausible Anworten. Tübingen. Narr.

Lewis, David. 1973. Counterfactuals. Cambridge, Mass. Harvard University Press.

Reis, Marga. 1982. Zum Subjektbegriff im Deutschen. Werner Abraham, ed. Satzglieder im Deutschen. Tübingen. Niemeyer. 171 - 211.

Reis, Marga. 1985. Mona Lisa kriegt zuviel - Vom sogenannten 'Rezipientenpassiv' im Deutschen. $\quad$ Linguistische Berichte 96. 140-155.

Vendler, Zeno. 1967. Linguistics and Philosophy. Ithaca. Cornell University Press.

Wegener, Heide. 1985. Der Dativ im heutigen Deutsch. Tübingen: Narr.

Wunderlich, Dieter. 1996. Dem Freund die Hand auf die Schulter legen. Gisela Harras und Manfred Bierwisch, eds. Wenn die Semantik arbeitet. Klaus Baumgärtner zum 65. Geburtstag. Tübingen. Niemeyer. 331<- 360.

Wunderlich, Dieter. 1997. CAUSE and the structure of verbs. Linguistic Inquiry 28. 27-68. 